MATEC Web of Conferences 6, 02002 (2013)

DOI: $10.1051 /$ matecconf $/ 20130602002$

(C) Owned by the authors, published by EDP Sciences, 2013

\title{
Concrete spalling sensitivity versus microstructure: Preliminary results on the effect of polypropylene fibers
}

\author{
Chiara Rossino ${ }^{1}$, Francesco Lo Monte ${ }^{2}$, Stefano Cangiano ${ }^{1}$, Roberto Felicetti ${ }^{2}$ \\ and Pietro G. Gambarova²
}

1 CTG Italcementi Group, Bergamo, Italy

2 Politecnico di Milano, Milan, Italy

\begin{abstract}
The phisyco-mechanical processes triggering concrete explosive spalling are related to the heat-induced micro- and meso-structural changes. To have new information on concrete properties at the microstructural level, as well as on how concrete spalling sensitivity is affected by polypropylene and steel fibers, and by aggregate type, ordinary and high-performance concretes are investigated in this research project, after being heated to different temperatures. The focus is on the relationship among porosity, vapor permeability, pore pressure and microcracking inside the cementitious matrix. Polypropylene fibers are shown to increase the total porosity, to favor microcracking and to reduce significantly pore pressure, to the advantage of concrete resistance to explosive spalling, whose risk is markedly reduced - or even zeroed.
\end{abstract}

\section{INTRODUCTION}

Explosive spalling is a critical and still highly-debated issue, especially in high-performance concrete (HPC), which is particularly sensitive to spalling because of its denser matrix with respect to ordinary or normal-strength concrete (NSC), because of HPC's lower water/binder ratio, that is one of the conditions required to increase concrete compressive strength [1]. Spalling ensues from different physico-mechanical phenomena interacting during the heating process: (a) pore-pressure increase due to water vaporization; (b) self-stresses induced by the thermal gradients; and (c) load-induced stresses. While points (b) and (c) are strictly related to geometrical and structural configuration, point (a) has to do with concrete microstructure (and more specifically, to pore structure). The high spalling sensitivity of HPC, in fact, derives mostly from mass transport properties of its matrix, which is denser and finer than that of NSC. Consequently, water and vapor expulsion is obstructed, and pore-pressure release is impeded [2]. Polypropylene-pp fibers are commonly added to HPC mixes to decrease spalling sensitivity by reducing pore pressure. This is possible because pp fibers melt and degrade above $165^{\circ} \mathrm{C}$ [3], and generate not only new voids (corresponding to their volume), but create a network of micropores connecting the already-existing pores. In such a way, continuous channels are formed, that allow the vapor to migrate inside the material, towards cooler and lower-pressure zones, and the risk of explosive spalling is reduced [4-6]. On the other hand, it is well known that adding steel fibers (sf) increases concrete toughness in the post-peak range, and reduces spalling sensitivity too, even if less efficiently than pp fibers [7]. (Steel fibers, however, prevent the pieces from breaking off the concrete mass).

In this study, the attention is focused on the microstructural changes induced by high temperature in HPC. A number of different-grade mixes is considered, with/without pp or steel fibers, that come in different types and amounts. The aim is to link material's microstructure to the physical and mechanical properties in order to shed new light on the interaction between concrete behaviors at the micro- and macro-scale, with particular reference to pore pressure and spalling. In this way, mix optimization to

This is an Open Access article distributed under the terms of the Creative Commons Attribution License 2.0, which permits unrestricted use, distribution, and reproduction in any medium, provided the original work is properly cited. 


\section{MATEC Web of Conferences}

Table 1. Mix designs and mechanical properties of the concretes; $\mathrm{sp}=$ acrylic superplasticizer; $\mathrm{w}=\mathrm{water} ; \mathrm{b}=$

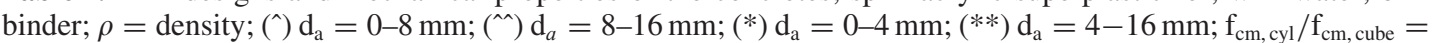
concrete compressive strength on cylinders/cubes at 28 days.

\begin{tabular}{|c|c|c|c|c|c|c|c|c|c|c|}
\hline Mix No & $\mathbf{1}$ & 2 & 3 & 4 & 5 & 6 & 7 & 8 & 9 & 10 \\
\hline \multirow[t]{2}{*}{ Mix designation } & $45-S$ & 70-S & 95-S & 70-C & 70-S & 70-S & 70-S & 70-S & 70-S & 70-S \\
\hline & & & & & Pm 0.5 & Pm 1 & Pm 2 & Pf 2 & Sf 40 & Sf 60 \\
\hline CEM I $\left(\mathrm{kg} / \mathrm{m}^{3}\right)$ & 400 & 400 & 480 & 400 & 400 & 400 & 400 & 400 & 400 & 400 \\
\hline calc. Filler $\left(\mathrm{kg} / \mathrm{m}^{3}\right)$ & 200 & - & - & - & & & & & & \\
\hline GGBS $\left(\mathrm{kg} / \mathrm{m}^{3}\right)$ & - & 200 & 300 & 200 & 200 & 200 & 200 & 200 & 200 & 200 \\
\hline $\operatorname{SC}_{\operatorname{gravel}^{\wedge}}\left(\mathrm{kg} / \mathrm{m}^{3}\right)$ & 883 & 860 & 821 & - & 860 & 860 & 860 & 860 & 860 & 860 \\
\hline $\operatorname{SC} \operatorname{aggr}^{\wedge}\left(\mathrm{kg} / \mathrm{m}^{3}\right)$ & 610 & 699 & 667 & - & 699 & 699 & 699 & 699 & 699 & 699 \\
\hline calc. sand* $\left(\mathrm{kg} / \mathrm{m}^{3}\right)$ & - & - & - & 800 & - & - & - & - & - & - \\
\hline calc. aggr** $\left(\mathrm{kg} / \mathrm{m}^{3}\right)$ & - & - & - & 749 & - & - & - & - & - & - \\
\hline $\mathrm{pp} \operatorname{mnf}\left(\mathrm{kg} / \mathrm{m}^{3}\right)$ & - & - & - & - & 0.5 & 1 & 2 & - & - & - \\
\hline $\mathrm{pp}$ fbr $\left(\mathrm{kg} / \mathrm{m}^{3}\right)$ & - & - & - & - & - & - & - & 2 & - & - \\
\hline steel fibers $\left(\mathrm{kg} / \mathrm{m}^{3}\right)$ & - & - & - & - & - & - & - & - & 40 & 60 \\
\hline $\mathrm{sp}\left(\mathrm{kg} / \mathrm{m}^{3}\right)$ & 1.8 & 2.76 & 12.79 & 2.04 & 2.76 & 2.76 & 2.76 & 2.76 & 2.76 & 2.76 \\
\hline $\mathrm{w} / \mathrm{b}$ ratio & 0.56 & 0.36 & 0.24 & 0.36 & 0.36 & 0.36 & 0.36 & 0.36 & 0.36 & 0.36 \\
\hline$\rho_{\text {fresh state }}\left(\mathrm{kg} / \mathrm{m}^{3}\right)$ & 2340 & 2390 & 2440 & 2380 & 2380 & 2370 & 2350 & 2390 & 2410 & 2430 \\
\hline $\mathrm{f}_{\mathrm{cm}, \mathrm{cyl}} / \mathrm{f}_{\mathrm{cm}, \text { cube }}(\mathrm{MPa})$ & $40 / 47$ & $62 / 72$ & 90/99 & $64 / 73$ & $63 / 70$ & $60 / 70$ & $60 / 69$ & $61 / 72$ & $63 / 72$ & $60 / 73$ \\
\hline
\end{tabular}

limit the risk of concrete spalling becomes viable, and the designer will eventually be enabled to control such a complex phenomenon as spalling.

\section{EXPERIMENTAL PROGRAM}

\subsection{Materials and concrete mix designs}

This experimental project includes 10 concrete mixes, differing for their compressive strength, type and content of fibers, as well as for the aggregate type. The cement type and class were selected in order to keep the volumetric fraction of the cementitious matrix as constant as possible. CEM I, 42.5 R was used in combination with Ground Granulated Blast Furnace Slag (GGBS), as shown in Table 1. Three concrete grades are considered with $\mathrm{f}_{\mathrm{cm} \text {,cube }} \geq 45,70,95 \mathrm{MPa}$ (determined at 28 days on $100 \mathrm{~mm}$-side cubes), whose mix design includes silico-calcareous (SC) aggregate (Mixes 45-S, 70-S, 95-S). For the intermediate strength class $\left(\mathrm{f}_{\mathrm{cm}}\right.$, cube $\left.\geq 70 \mathrm{MPa}\right)$, pp and steel fibers have been added. Polypropylene fibers are either monofilament fibers (mnf, $\mathrm{L}=12 \mathrm{~mm} ; \varnothing_{\mathrm{eq}}=20 \mu \mathrm{m}$, extruded straight fibers treated with a surfactant agent), designed specifically to prevent concrete spalling [5], or fibrillated fibers (fbr, $\mathrm{L}=12 \mathrm{~mm}, \varnothing_{e q}=48 \mu \mathrm{m}$, straight fibers obtained by longitudinally cutting pp stripes) generally used to limit early-age shrinkage [8]. Monofilament fibers come in three contents: $0.5,1.0$ and $2.0 \mathrm{~kg} / \mathrm{m}^{3}$ (Mixes 70-S-Pm 0.5, 70-S-Pm 1 and 70-S-Pm 2, respectively), while fibrillated fibers come in one content $\left(2 \mathrm{~kg} / \mathrm{m}^{3}\right.$, Mix 70-S-Pf) and steel fibers in two contents (40 and $60 \mathrm{~kg} / \mathrm{m}^{3}$, Mixes $70-\mathrm{S}-\mathrm{Sf} 40$ and 70-S-Sf 60, respectively).

The aggregate-type role was evaluated by comparing Mixes 70-S and 70-C, with silico-calcareous and calcareous aggregates, respectively; both mixes had no fibers. The ten mixes and their properties at the fresh state, as well as their compressive strength at 28 days, are reported in Table 1 (see [9-11] for the testing procedures). In the mix designs, the binder is a combination of CEM I and GGBS, except in Mix 45-S, where GGBS is replaced with a calcareous filler. The surfactant agent covering the monofilament pp fibers is responsible for the decrease of the density at increasing values of the fiber content (see Table 1). Cubes with $100 \mathrm{~mm}$-side were cast to investigate the microstructure and to 
measure pore pressure, while cylinders $(\varnothing=150 \mathrm{~mm}, \mathrm{~h}=300$ or $50 \mathrm{~mm})$ were used to evaluate the compressive strength at 28 days or to measure vapor permeability.

All specimens were cured in water for 28 days according to [12]. The cubes were later kept at $10^{\circ} \mathrm{C}$ for further 28 days, in order to slow down the hydration process.

\subsection{Microstructural characterization in residual conditions}

In order to characterize the mixes from the microstructural point of view and to investigate heat-induced effects, several experimental techniques were used:

- Scanning Electron Microscopy (SEM): both polished sections and fractured surfaces were examined by means of a Zeiss EVO MA15 (thermoionic source in Lanthanum hexaboride $\mathrm{LaB}_{6}$ );

- Mercury Intrusion Porosimetry (MIP) by means of Pascal 140 and 240 porosimeters (Mercury intrusion rate $=5$ and extrusion rate $=6$ );

- X-Ray Diffraction (XRD): the analyses were performed by using a Bruker D8 Advance Diffractometer; data acquisition was performed for different values of the diffraction angle $2 \theta$ comprised between $5^{\circ}$ a $70^{\circ}$ with increments of $0.02^{\circ}$ and a time steps of 0.4 seconds;

- Thermogravimetric Analysis (TGA): thermal ramp between $25^{\circ} \mathrm{C}$ and $975^{\circ} \mathrm{C}$ with heating rate $10^{\circ} \mathrm{C} / \mathrm{min}$, in nitrogen atmosphere; test set-up: Mettler Toledo TGA/SDTA $851^{\mathrm{e}}$.

First of all, small cylinders $(\varnothing=20 \mathrm{~mm}, \mathrm{~h}=100 \mathrm{~mm}$ ) suitable for microstructural analysis were cored from a number of concrete cubes. The tests were performed in residual conditions considering five target temperatures: 20 (reference temperature), $105,250,500$ and $750^{\circ} \mathrm{C}$. The specimens were heated inside an electric furnace (heating rate $=1{ }^{\circ} \mathrm{C} / \mathrm{min}$ ); once the target temperature was reached, that temperature was kept constant for 2 hours, followed by the cooling phase (coolingrate $=-0.25^{\circ} \mathrm{C} / \mathrm{min}$ down to $200{ }^{\circ} \mathrm{C}$ and then natural cooling inside the closed furnace). So far, the tests have been performed on Mixes 45-S, 70-S, 70-S-Pm1, 70-S-Pm2 and 95-S; as for the remaining mixes, the analyses are in progress.

\subsection{Physical and mechanical characterization}

Concrete samples were characterized from the physico-mechanical point of view by measuring pore pressure and permeability on virgin specimens $\left(20^{\circ} \mathrm{C}\right.$, at 28 days, according to [13]). Pore pressure was measured during the heating process (see Section 3.3), in order to identify a possible relationship between the spalling sensitivity (that is related to the maximum pore pressure) and either the concrete porosity or the concrete vapor permeability. A special experimental set-up was designed and built [14].

\section{RESULTS AND DISCUSSION}

\subsection{Microstructural characterization}

\subsubsection{Mercury intrusion porosimetry (Mixes 2, 6, 7)}

The diagrams of the cumulative pore volume and of the relative volume obtained by means of MIP are plotted in Fig. 1 for three concrete mixes, as a function of pore radius. For the sake of comparison, in Fig. 1 reference is made to Mix 70-S with and without fibers (Mixes 70-S, 70-S-Pm 1 and 70-S-Pm 2). The porosity of the specimens treated at $105^{\circ} \mathrm{C}$ is considered as a reference, since the evaporable water has been expelled; the porosity at $20^{\circ} \mathrm{C}$ refers to room-conditioned specimens. Figure 1 refers to 70-S series and shows that increasing temperature brings in increasing values of the cumulative pore volume. At the same time, adding pp fibers brings in higher values for the cumulative pore volume, at any temperature. In Fig. 1b,d,f, the diagrams of pore-size distribution, for different temperatures, move towards larger-radius pores at increasing temperatures, because of the progressive expulsion of both free and bound water, with consequent increase in pore size. The most significant results concern the 

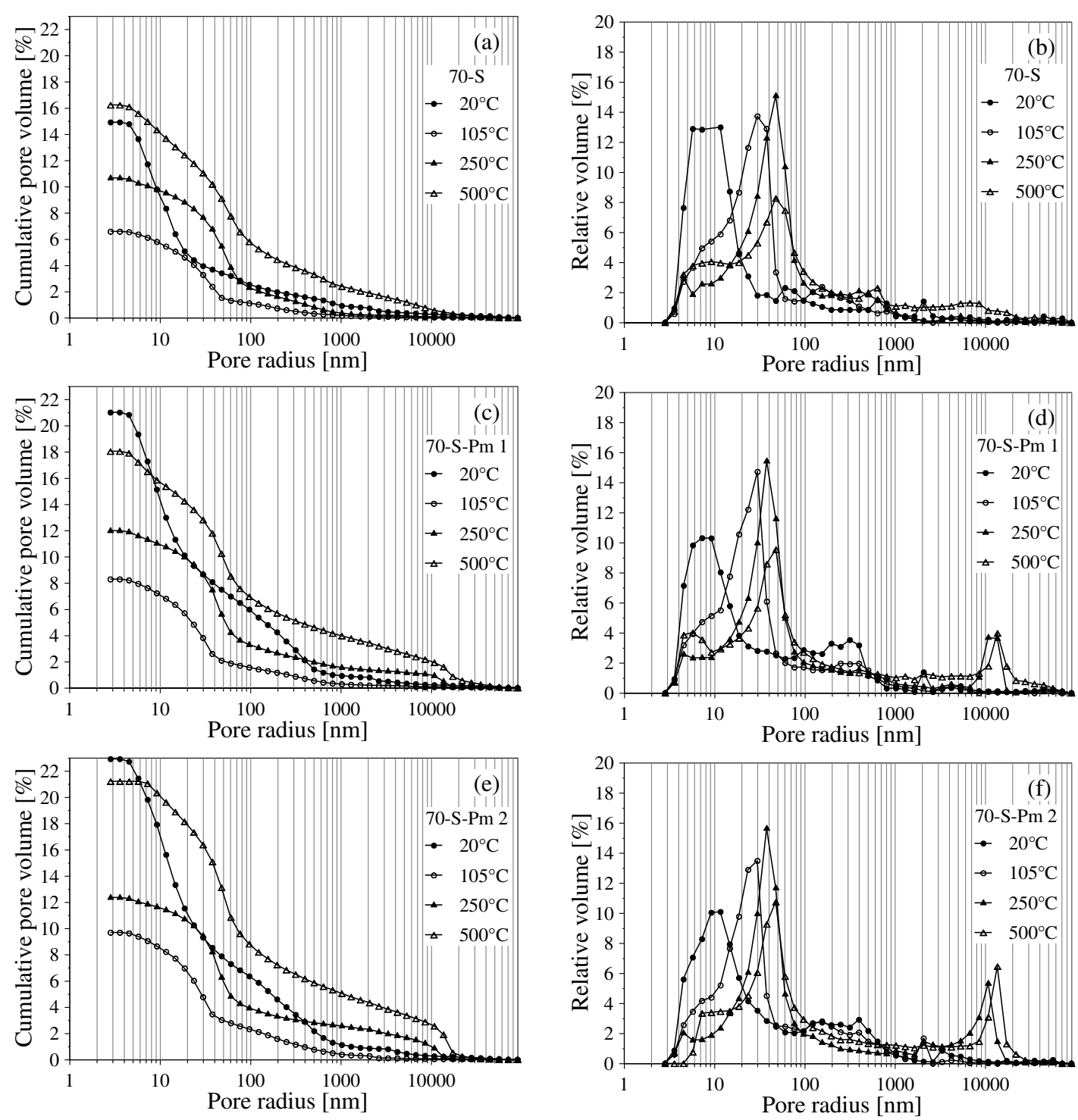

Figure 1. Cumulative pore volume for Mixes 70-S (a), 70-S-Pm1 (c), 70-S-Pm2 (e); and relative volume for Mixes 70-S (b), 70-S-Pm1 (d) and 70-S-Pm2 (f) as a function of pore radius.

pore distribution in the mixes containing pp fibers: microporosities (whose size is of the same order of magnitude as the diameter of monofilament pp fibers) appear in Mixes 70-S-Pm1 and 70-S-Pm2, after being heated to 250 and $500^{\circ} \mathrm{C}$ as a consequence of the melting/degradation of the fibers. The higher the pp-fiber content, the higher the relative volume peaks and the porosity generated by the thermal treatment, as discussed in Section 2.1. Figure 2 shows the values of the total porosity as a function of the temperature for the different mixes. As expected, higher-grade concretes have lower porosity at any temperature. Polypropylene fibers induce a significant increase of the porosity above $250{ }^{\circ} \mathrm{C}$. Roomconditioned specimens $\left(20^{\circ} \mathrm{C}\right)$ show a reduced porosity as the pore volume is only partially accessible to mercury. The content of evaporable water at $105^{\circ} \mathrm{C}$ is about $2 \%$ by volume). 


\section{IWCS 2013}

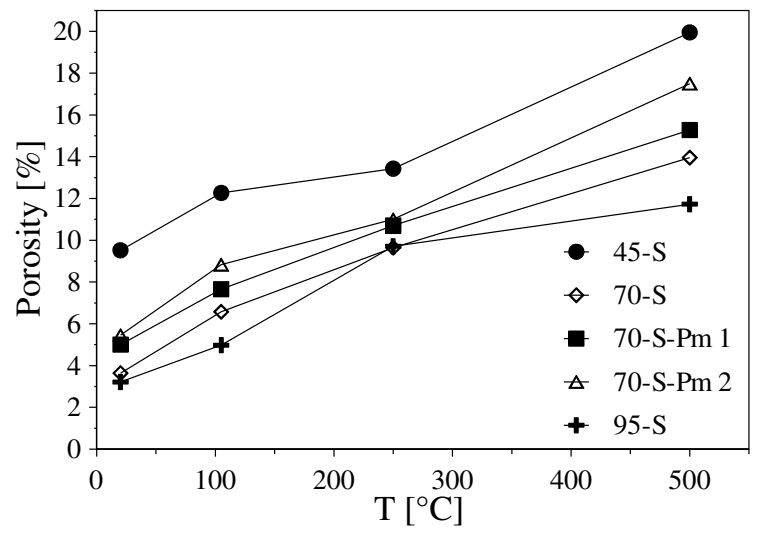

Figure 2. Total porosity as a function of the temperature.

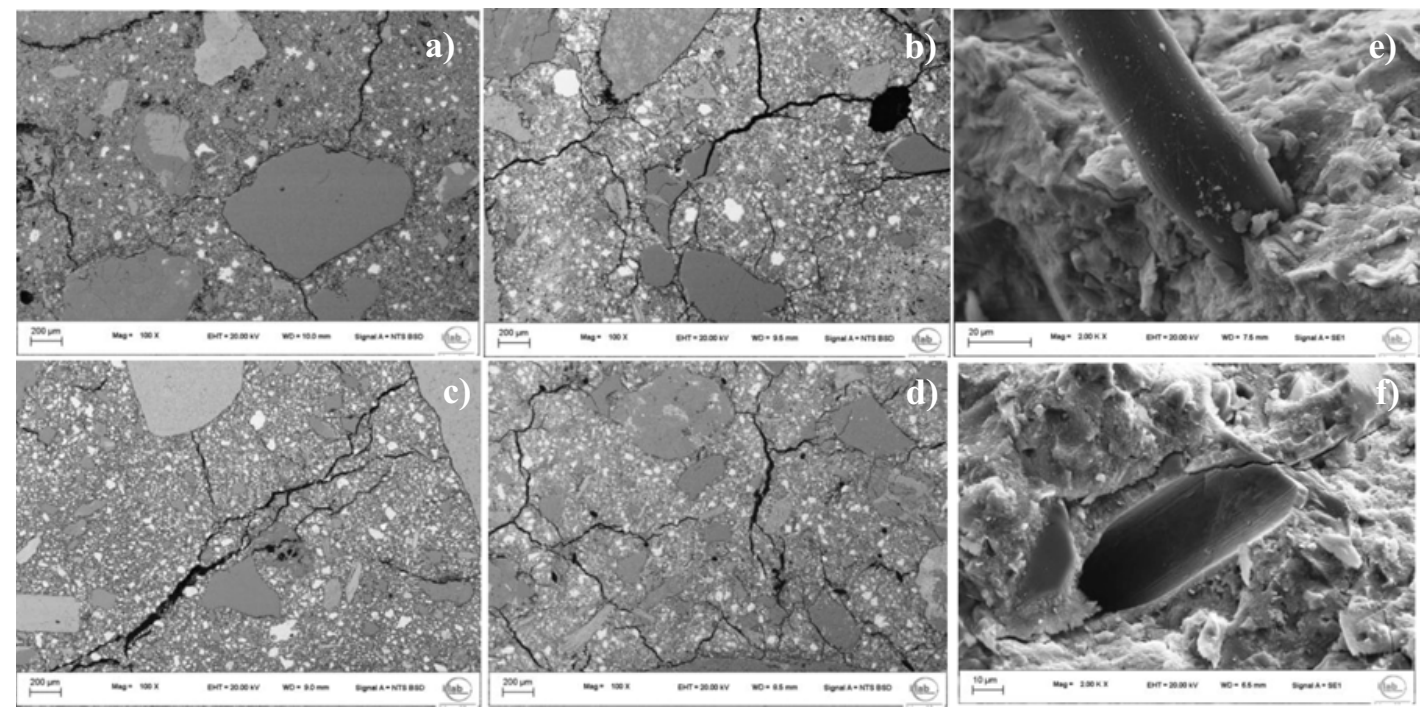

Figure 3. BSE images (magnitude: $100 \mathrm{X}$ ) of polished sections heated to $500^{\circ} \mathrm{C}$ : (a) Mix 45-S; (b) Mix 70-S; (c) Mix 95-S; and (d) Mix 70-S-Pm 2; and SE images (magnitude 2.00 KX) of fractured sections, Mix 70-S-Pm 2: (e) a typical monofilament fiber in the virgin material, not heat treated; and (f) typical void left by a fiber after heating to $250{ }^{\circ} \mathrm{C}$.

\subsubsection{Scanning electron microscopy (Mixes 1, 2, 3, 6, 7)}

The images obtained by means of SEM after concrete heating are shown in Fig. 3. In the case of polished sections the technique based on Back Scattered Electrons - BSE was used, while fractured surfaces were examined by means of Secondary Electrons - SE. Figures 3a-d show that microcracking occurs after heating to $500{ }^{\circ} \mathrm{C}$. In addition, cracking in Mix 45-S (Fig. 3a) is hardly distributed, being mainly located at the aggregates-matrix interface.

In Mixes 70-S and 95-S (Figs. 3b,c), cracking appears more distributed and extended to the cementitious matrix. Adding fibers seems to make cracks more distributed (Fig. 3d). Moreover, observing Mix 70-S-Pm2 after heating to $250^{\circ} \mathrm{C}$ (Fig. 3f), the spaces originally occupied by pp fibers 


\section{MATEC Web of Conferences}
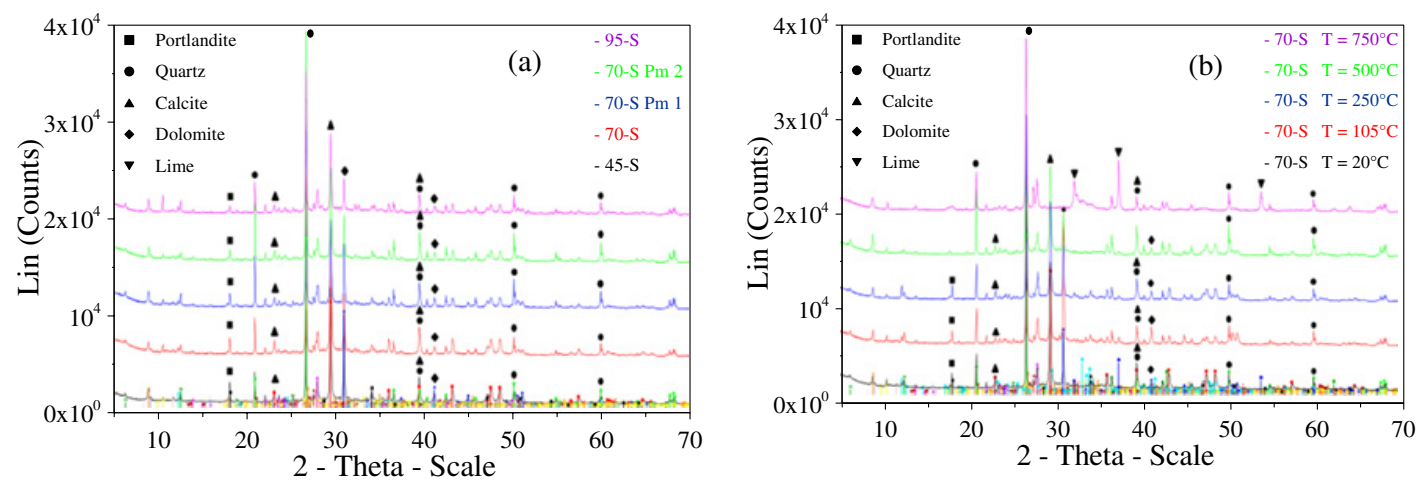

Figure 4. XRD curves for: (a) Mixes 45-S, 70-S, 70-S-Pm1, 70-S-Pm2 and 95-S at $20^{\circ} \mathrm{C}$; and (b) for Mixes $70-\mathrm{S}$ at all temperatures (the horizontal axes are shifted vertically).
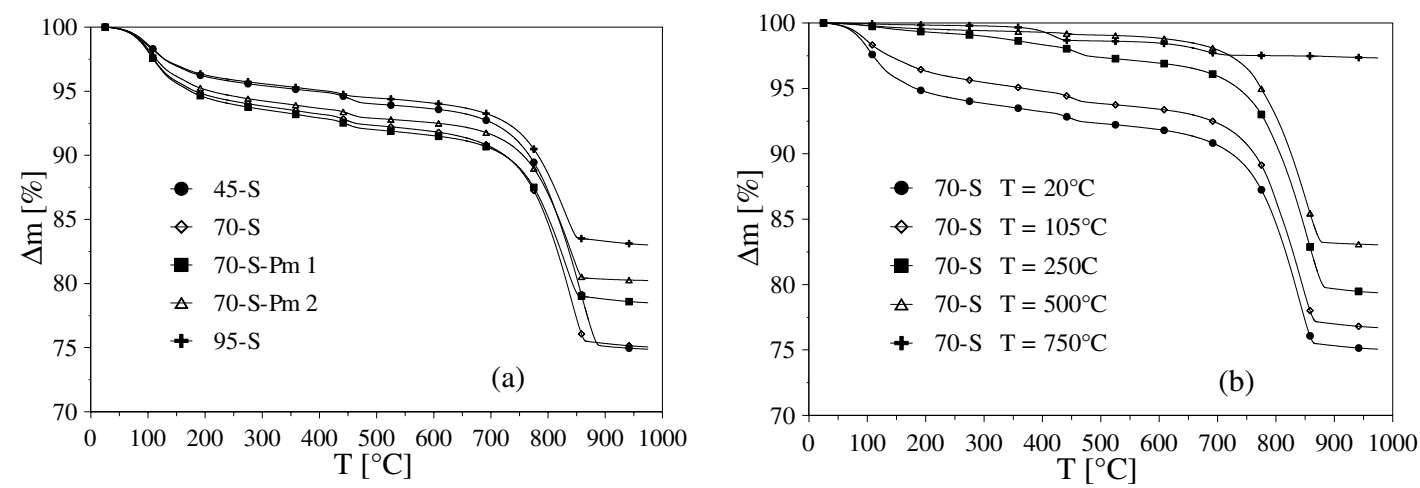

Figure 5. TGA curves for Mixes 45-S, 70-S, 70-S-Pm 1, 70-S-Pm 2 and 95-S at $20^{\circ} \mathrm{C}$; and (b) TGA curves for Mix 70-S for all temperatures.

appear empty, because of the melting and subsequent disappearance of the fibers, and a few new cracks propagate through the channels left free by the fibers.

\subsubsection{X-ray diffraction and thermogravimetric analysis (Mixes 1, 2, 3, 6, 7)}

The XRD curves pertaining to 5 mixes in virgin conditions (no heating, $\mathrm{T}=20^{\circ} \mathrm{C}$ ) are plotted in Fig. $4 \mathrm{a}$, while in Fig. $4 \mathrm{~b}$ the curves pertaining to Mix 70-S are grouped together from 20 to $750{ }^{\circ} \mathrm{C}$. In Fig. $4 \mathrm{a}$, the crystalline phases of the aggregate can be recognized, and specifically quartz, dolomite and calcite. The portlandite content decreases for increasing values of GGBS content; at the same time, the compressive strength increases (as should have been expected). It is worth noting that no fiber influence has been detected on cement hydrated phases. As shown in Fig. 4b, increasing the temperature leads to the transformation of portlandite into lime $(\mathrm{CaO})$, due to the dehydration process taking place between 400 and $500^{\circ} \mathrm{C}$; lime comes also from the decarbonation of calcite above $650{ }^{\circ} \mathrm{C}$ [15]. XRD analysis shows no $\beta$-quartz (above $750^{\circ} \mathrm{C}$ ) because of the slow cooling of the concrete to room temperature, that turns $\beta$-quartz into $\alpha$-quartz (due to process reversibility). The transformations resulting from the crystalline phases can also be observed in TGA curves. In Fig. 5a the curves concerning five mixes are plotted in virgin conditions, while in Fig. 5b only one mix is considered for five thermal levels (Mix 70-S). TGA curves indicate a first very small mass loss between 400 and $500^{\circ} \mathrm{C}$, because of portlandite 
IWCS 2013
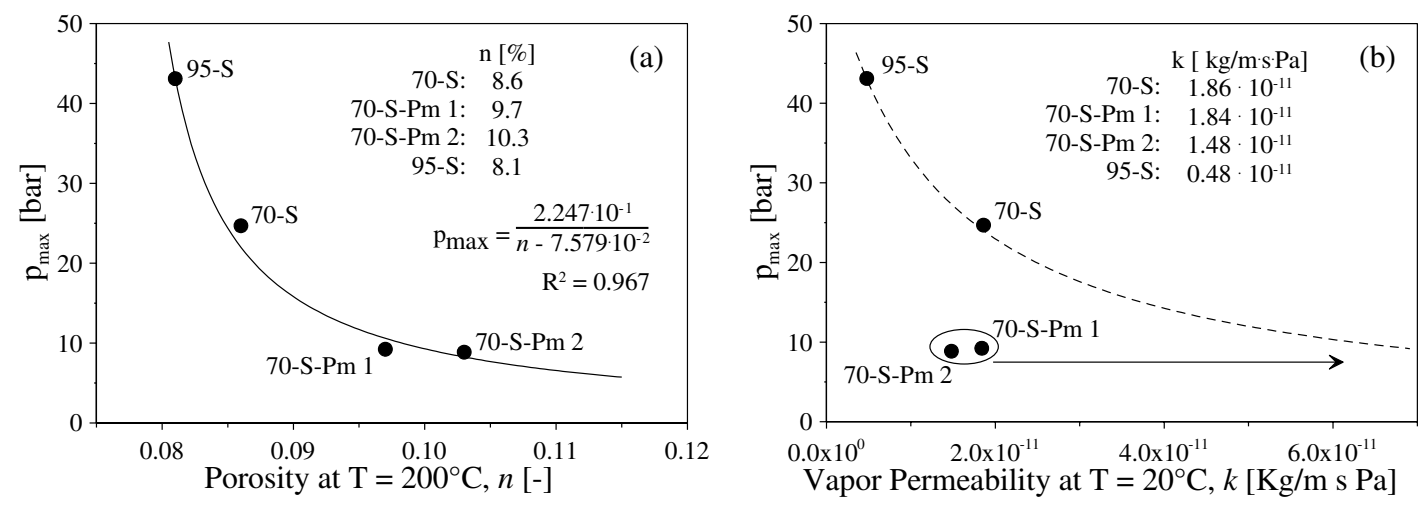

Figure 6. Peak values of the pore pressure as function of concrete porosity at $20{ }^{\circ} \mathrm{C}$ (a); and of vapor permeability at room temperature (b).

dehydration; after $700^{\circ} \mathrm{C}$, a more significant mass loss occurs, because of the decarbonation of calcite, as already shown by XRD analysis.

In Fig. $5 \mathrm{~b}$ it is worth noting that the mass-loss rate has a maximum between 100 and $200{ }^{\circ} \mathrm{C}$ (due to the expulsion of both the free and the bound water). The same occurs for the mass loss due to portlandite dehydration and calcite decarbonation, that tend to grow weaker above $500^{\circ} \mathrm{C}$ and $750^{\circ} \mathrm{C}$, respectively.

\subsection{Porosity, vapor permeability and pore pressure}

The experimental results concerning the vapor permeability of the ten mixes show that the lower the compressive strength, the higher the vapor permeability, in agreement with the porosity trend (see Fig. 6). Adding pp fibers does not significantly affect the vapor permeability with respect to the plain $\operatorname{mix}($ Mix 70-S).

Pore pressure was measured on $100 \mathrm{~mm}$-side cubes with the heating and measuring system developed in [14]. Four mixes were investigated (Mixes 70-S, 70-S-Pm 1, 70-S-Pm 2 and 95-S). The pore pressure was measured during the heating process until the maximum value was detected. In order to minimize thermal stresses, the heating rate was rather small $\left(0.5^{\circ} \mathrm{C} / \mathrm{min}\right)$. The maximum pressure occurred in a narrow thermal range $\left(180-220^{\circ} \mathrm{C},[14]\right)$.

Since the evolution of pore pressure during the heating process is controlled by vapor permeability (according to Darcy's law [16]) and vapor diffusion (according to Fick's law [16]), both mass transport processes being related to concrete porosity, it is rather interesting to plot the maximum values of pore pressure as a function of total porosity (at $200^{\circ} \mathrm{C}$, see Fig. 6a) and vapor permeability (at $20^{\circ} \mathrm{C}$, see Fig. 6b). In Fig. 6a the experimental values can be easily fitted by means of a hyperbolic curve with appreciable statistical significance; this confirms the major role played by the total porosity in moisture transport and vaporization, as well as on concrete strength [17]. (For the mathematical formulation of the curve and the $\mathrm{R}^{2}$ value, see the inserts inside Fig. 6a). Figure $6 \mathrm{~b}$ shows that the decrease of pore pressure is consistent with the increase of vapor permeability at $20^{\circ} \mathrm{C}$ only for plain mixes (Mixes 70-S and 95-S), while for fiber-reinforced mixes (Mixes 70-Pm1 and 70-Pm2) the vapor permeability at $20^{\circ} \mathrm{C}$ does not seem to be a proper parameter to describe the decrease of the peak pressure in the pores as a function of the concrete type. This fact can be ascribed to the much more significant increase of the permeability with the temperature in fiber-reinforced concrete compared to plain concrete (due to the melting and degradation of the fibers - above $165^{\circ} \mathrm{C}$ - and to the formation of new microcracks starting from the voids left by the fibers [4]). Unfortunately, vapor permeability in heated specimens has not been measured so far in this project, but tests have been planned and will be performed shortly. 


\section{MATEC Web of Conferences}

\section{CONCLUDING REMARKS}

The microstructural observations and the physico-mechanical tests concerning various ordinary and high-performance mixes (different aggregates, fibers and fiber contents) allow to make some comments and to draw some preliminary conclusions:

- At any temperature, high-performance concretes exhibit a total porosity, that is definitely lower compared to ordinary concretes, mainly owing to the reduced water/binder ratio in the former materials; on the other hand, cracking seems more distributed in HPC and tends to propagate through the cementitious matrix, while in ordinary concrete cracking is more concentrated at the aggregate-matrix interface.

- At any temperature, pp fiber-reinforced concrete exhibits a higher total porosity than plain concrete; this effect increases with the fiber amount; during - or after fibers melting/degradation (above $165^{\circ} \mathrm{C}$ ) - new microcracks form and propagate from the channels left free by pp fibers.

- Both Thermogravimetric and X-Ray Diffraction analyses indicate that monofilament fibers do not affect the evolution of concrete hydrated phases, as should be expected.

- The peak pressure in the pores is strictly related to the porosity, in both plain and fibrous mixes (in these latter mixes, porosity increases markedly after fibers melting and degradation); the relationship between peak pressure and porosity is adequately described by an hyperbole. The same seems to be true for the peak pressure as a function of vapor permeability, although this has been validated so far for plain mixes only. Further tests will be performed on fibrous mixes after heating, in order to have further information on to quantify the increased permeability ensuing from (a) fiber melting/degradation, with the formation of new voids, and (b) the creation of microcracks propagating through those voids, which are the basic mechanisms of spalling mitigation in fiberreinforced concrete.

\section{References}

[1] ACI American Concrete Institute, ACI 363 R-92, State of the art Report on High Strength Concrete, ACI Commetee 363, ACI Manual of Concrete Practice (Part 5), 2007.

[2] Anderberg Y., Spalling phenomena of HPC, Proceedings of International Workshop on Fire Performance of High-Strength Concrete, NIST, L.T. Phan, N.J. Carino, D. Duthinh, E. Garboczi (Eds.), NIST, Gaithersburg, MD, USA, 13-14 February, 69-73, 1997.

[3] CTG Italcementi Group, Internal Technical Report, 2013.

[4] Kalifa P., Chéné G., Gallé C., High-Temperature Behaviour of HPC with PolyPropylene Fibers: From Spalling to Microstructure, Cement and Concrete Research, 31, 1487-1499, 2001.

[5] Khoury G.A., Polypropylene Fibres in Heated Concrete. Part 2: Pressure Relief Mechanisms and Modelling Criteria, Magazine of Concrete Research, 60 (3), 189-204, 2008.

[6] Pistol K., Weise F., Meng B., Schneider U., The Mode of Action of Polypropylene Fibres in High Performance Concrete at High Temperatures, Proceedings of $2^{\text {nd }}$ International RILEM Workshop on Concrete Spalling due to Fire Exposure, E.A.B. Koenders, F. Dehn (Eds.), Delft, The Netherlands, 5-7 October, 289-296, 2011.

[7] Bhargava P., Sharma U.K., Kaushik S.K., Compressive Stress-Strain Behavior of Small Scale Steel Fibre Reinforced High Strength Concrete Cylinders, Journal of Advanced Concrete Technology, 4 (1), 109-121, 2006.

[8] Bayasi Z., McIntyre M., Application of Fibrillated Polypropilene Fibers for Restraint of Plastic Shrinkage Cracking in Silica Fume Concrete, Materials J., 99 (4), 337-344, 2002.

[9] CEN European Committee for Standardization, EN 12350-6, Testing fresh concrete - Density, European Standard.

[10] CEN European Committee for Standardization, EN 12350-2, Testing fresh concrete - Slump test, European Standard. 
[11] CEN European Committee for Standardization, EN 12390-3, Testing hardened concrete Compressive strength of test specimens, European Standard.

[12] CEN European Committee for Standardization, EN 12390-2, Testing hardened concrete - Part 2 : Making and curing specimens for strength test, European Standard.

[13] CEN European Committee for Standardization, EN 1015-19, Methods of test for mortar for masonry. Determination of water vapour permeability of hardened rendering and plastering mortars, European Standard.

[14] Felicetti R. and Lo Monte F., Concrete Spalling: Interaction between Tensile Behavior and Pore Pressure during Heating, Proceedings of the $3^{\text {th }}$ International Workshop on Concrete Spalling due to Fire Exposure, Paris, France, 25-27 September, 2013, in press.

[15] Alonso C., Fernandez L., Dehydration and rehydration processes of cement pastes exposed to high temperature environments, Journal of Material Science, 39, 3015-3024, 2004.

[16] Gawin D., Pesavento P and Schrefler B.A., What physical phenomena can be neglected when modelling concrete at high temperature? A comparative study. Part 1: Physical phenomena and mathematical model, International Journal of Solids and Structures, 48, 1927-1944, 2011.

[17] Guerrini G.L., Gambarova P.G. and Rosati G.P., Microstructure of High-Strength Concrete Subjected to High Temperature, Proc. Int. Workshop "Fire Design of Concrete Structures: What now? What next?", P.G. Gambarova, R. Felicetti, A. Meda and P. Riva (Eds.), pub. by Starrylink (Brescia, Italy), Milan, Italy, 2-3 December 2004, 89-94, 2005. 